\title{
Buccal mucosa graft urethroplasty in a case of urethral amyloidosis presenting with long anterior urethral stricture
}

\author{
Dmitry Kurbatov, MD; ${ }_{i}^{*}$ Borko Stojanovic, MD; Sergey Dubskiy, MD; ${ }^{*}$ Alex Lepetukhin, MD;* \\ Miroslav L. Djordjevic, $M D^{\dagger \xi}$
}

*Endocrinology Research Center, Andrology and Urology Department, Moscow, Russia; 'University Children's Hospital, Belgrade, Serbia; §School of Medicine, University of Belgrade, Serbia

Cite as: Can Urol Assoc J 2015;9(11-12):E830-3. http://dx.doi.org/10.5489/cuai.2957

Published online November 4, 2015.

\section{Abstract}

Urethral amyloidosis is a rare condition, but clinically relevant because it can mimic urothelial carcinoma. We report a case of localized urethral amyloidosis presenting with a long anterior urethral stricture. We used extensive grafts of buccal mucosa for standard augmentation urethroplasty, with a successful outcome at the 2-year follow-up.

\section{Introduction}

Primary localized amyloidosis of the urethra, first described by Tilip, ${ }^{1}$ is a rare condition with fewer than 50 cases reported to date. Its true incidence is probably underestimated, since urethroscopy in an early stage of urethral amyloidosis reveals only simple fibrotic strictures that lead to the conclusion that a biopsy is not required. The clinical presentation usually resembles obstructive voiding symptoms, while hematuria can raise a suspicion of malignancy. ${ }^{2}$ Standard treatment has included a conservative approach and minimally invasive procedures without medium or long-term follow-up. Only a few cases of substitution urethroplasty have been reported, with good medium-term outcomes. ${ }^{3}$ We report the use of a buccal mucosa graft for urethroplasty in our case of localized urethral amyloidosis presenting with a long anterior urethral stricture.

\section{Case report}

A 34-year-old man presented with a 5-year history and a recent worsening of his symptoms of weak stream, urinary frequency, and painful urination. Additionally, he reported he had suffered a gonococcal urethritis 10 years earlier. Upon physical examination, the patient's general status was unremarkable, with normally developed external genitalia and no signs of inflammation. Blood analysis showed no abnormalities, while urinalysis revealed 10000 white and 5000 red blood cells per millilitre of urine.

A subsequent ultrasound scan showed normal kidneys, prostate and testicles. The bladder wall was thickened up to $6 \mathrm{~mm}$, with significant post-micturition residual urine. The urethra was $145-\mathrm{mm}$ long with a $5-\mathrm{mm}$ thick wall, hyperechogenic and hypovascularized. Urinary flow rate was $5 \mathrm{~mL} / \mathrm{sec}$, maximally. Retrograde urethrogram showed a continuous narrowing of the penile urethra up to its bulbus (Fig. 1). At urethroscopy, proximal urethra was patent with intact mucosa, but it gradually narrowed into a significantly stenotic penile part with fibrotic changes and areas of inflamed mucosa.

The patient underwent augmentation urethroplasty under general anesthesia. A circular incision of the penile skin was made and the penis was degloved. Hyaline density of the urethra was observed. The complete penile urethra, up to the bulbus, was mobilized from cavernous bodies and incised dorsally (Fig. 2). Since the urethral mucosa presented with yellowish tuberous and hyaline density, multiple biopsies were made to exclude malignancy. Two long buccal mucosa grafts, sized $8 \times 2 \mathrm{~cm}$, were harvested from both inner cheeks due to the $15-\mathrm{cm}$ stricture length. After defatting, grafts were fixed and quilted to the corporal bodies by multiple interrupted stitches. The incised urethra was joined with the grafts over a 16-Fr silicone Foley catheter. Suprapubic urinary catheter was placed into the bladder for postoperative urine derivation.

The urethral catheter was removed 3 weeks later and good patency of the reconstructed urethra was confirmed by voiding cystourethrography (Fig. 3). The postoperative maximal flow rate was $24 \mathrm{~mL} / \mathrm{sec}$ and maintained in next 24 months up to $22 \mathrm{~mL} / \mathrm{sec}$. At this follow-up, the patient remained asymptomatic with no evidence of disease recurrence, penile deformity or erectile dysfunction.

Histopathology revealed a non-specific inflammatory reaction and amorphous amyloid deposits of the mucosa, which showed a positive reaction to Congo-red (Fig. 4a, 


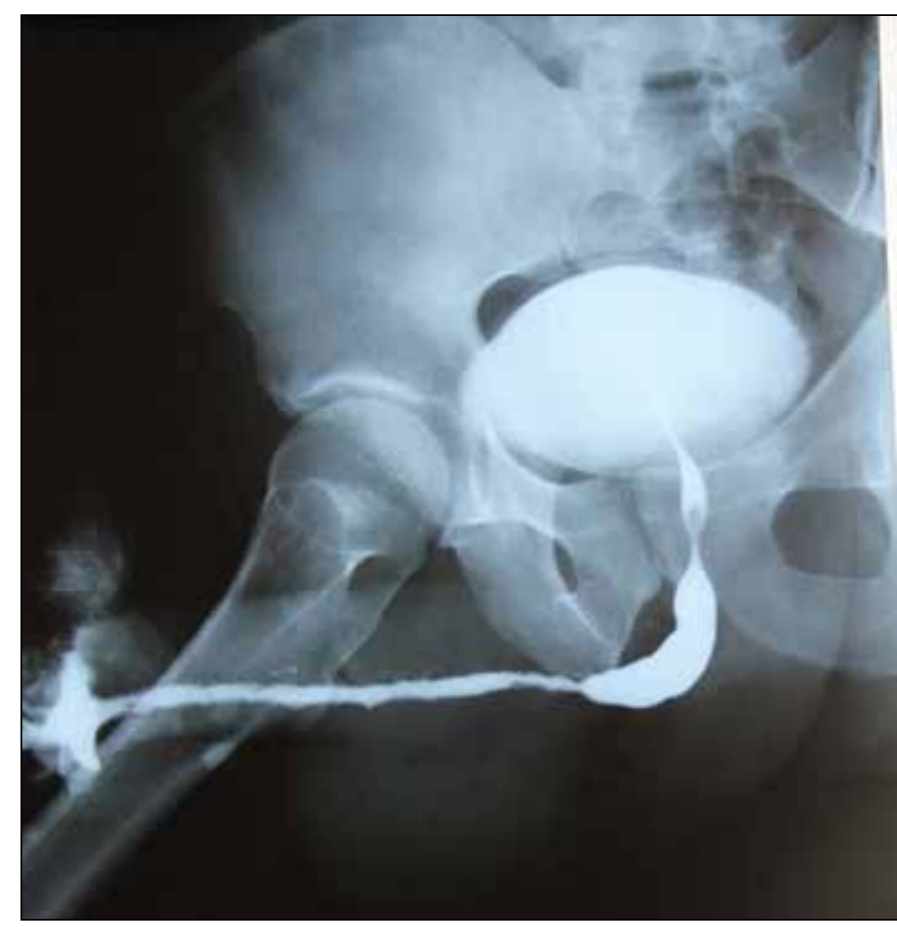

Fig. 1. Long stricture of anterior urethra was confirmed by voiding cystourethrography.

Fig. 4b). Additional rheumatology screening, skeletal survey, serum and urinary electrophoresis found no potential cause of systemic amyloidosis.

\section{Discussion}

Amyloidosis is characterized by extracellular deposition of a homogenous, eosinophilic, fibrillar protein, which may be systemically distributed or localized to a single organ. The urinary tract is a common site, with kidneys being most frequently affected, although combined lesions have also been reported. However, amyloid deposition in the lower genitourinary tract is rare condition, particularly in the urethra, but it is still clinically relevant because it can mimic urothelial carcinoma. ${ }^{4,5}$

Urethral amyloidosis occurs almost exclusively in men, with only 1 female case reported. It usually presents with painless hematuria, dysuria, obstructive voiding symptoms, as well as a spectrum of lower urinary tract symptoms. ${ }^{6-10}$ Cormio and colleagues reported an interesting case of urethral corpus spongiosum amyloidosis presenting with urethrorrhagia during erection and a palpable tumour in the penile urethra. ${ }^{11}$ Crook $^{2}$ and Mangera ${ }^{3}$ and colleagues reviewed the literature and summarized 40 and 45 cases with urethral amyloidosis, respectively. They concluded that only case reports or small case series of urethral amyloidosis have been described.

Generally, a clear histological diagnosis is needed to exclude malignancy and confirm the diagnosis of amyloido-

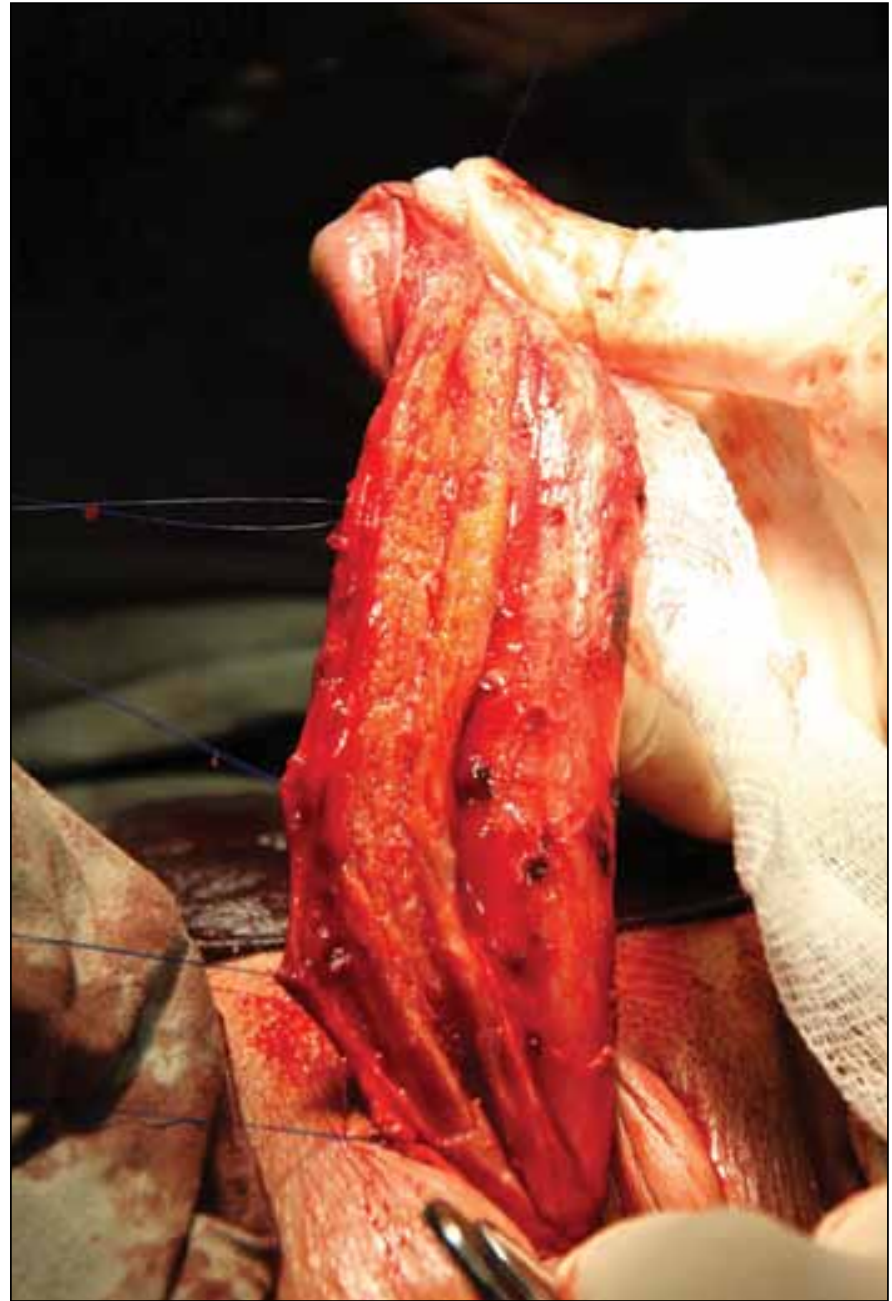

Fig. 2. Yellowish tuberous appearance of the urethral mucosa was found.

sis. Management of these cases is less well-described due to the short follow-up and limited description of the techniques used for its treatment. Crook and colleagues also proposed guidelines that include a conservative approach and followup for a maximum of 2 years. They found recurrence of the lesion in only 2 cases, suggesting that the condition is selflimiting and that follow-up beyond 2 years is unnecessary. ${ }^{2}$

Recently, the latest systematic review of the literature, in combination with personal experience, gave rise to a new perspective in the management of urethral amyloidosis. Mangera and colleagues described a progressive course of the disease in 3 of their 4 cases, when multiple repeated urethral procedures (urethrotomy, dilatation and intermittent self-dilation) can cause pan-urethral stricture disease. Two patients underwent urethral reconstruction using buccal mucosa graft and penile skin flap, and 1 case was solved with perineal urethrostomy. A good medium-term outcome was reported, without recurrence up to 18 months after surgery. ${ }^{3}$

In our case, urethral amyloidosis was presented as a long stricture of the anterior urethra, requiring surgical repair. 


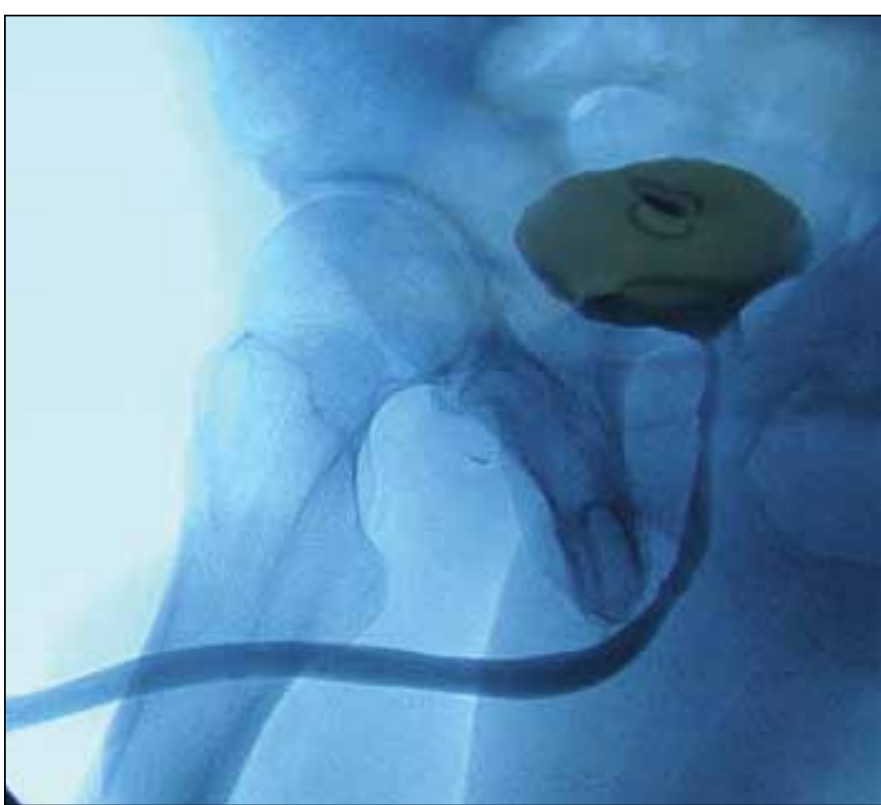

Fig. 3. Good patency of the neourethra was confirmed by postoperative urethrography.

Gonococcal urethritis, 10 years prior to the clinical presentation of amyloidosis, was suspected to have led to a predisposition, as in the other 5 reported cases. We used extensive grafts of buccal mucosa for standard augmentation urethroplasty with a successful outcome at the 2-year followup. Further monitoring is necessary due to the potentially progressive nature of this condition. Also, the oral mucosa has been found to be affected by amyloid deposits, so the grafted tissue, as a part of neourethra, may present a point of recurrence. ${ }^{12}$

\section{Conclusion}

Initially, the main management of urethral amyloidosis was strictly conservative, based on poor data with short followups. Recent reports indicate the progressive nature of the disease, showing that repeated urethrotomies and dilatations eventually lead to stricture recurrence, requiring surgical reconstruction of the urethra. Urethroplasty using buccal mucosa graft in primary localized urethral amyloidosis could be a good option. However, long-term follow-up is needed for further validation.

Acknowledgment: This paper is supported by Ministry of Science, Republic of Serbia, Project No. 175048.

Competing interests: The authors declare no competing financial or personal interests.

This paper has been peer-reviewed.

\section{References}

1. Tilip A. Ueber lokale tumor termices amyloid der harn rohre centrable. EAllg Path U Path Anat 1909;20:913.

2. Crook TJ, Koslowski M, Dyer JP, et al. A case of amyloid of the urethra and review of this rare diagnosis, its natural history and management, with reference to the literature. Scand J Urol Nephrol 2002;36:481-6. http://dx.doi.org/10.1080/003655902762467675

3. Mangera $\mathrm{A}$, Linton $\mathrm{KD}$, Fernando $\mathrm{M}$, et al. What is the evidence for the management of urethral amyloidosis? A systematic review of the literature. BJU Int 2012;109:1858-61. http://dx.doi.org/10.1111/ j.1464-410X.2011.10635.x

4. Merrimen JL, Alkhudair WK, Gupta R. Localized amyloidosis of the urinary tract: Case series of nine patients. Urology 2006;67:904-9. http://dx.doi.org/10.1016/i.urology.2005.11.029

5. Biyani CS, Fitzmaurice RJ, Upsdell SM. Localized amyloidosis of the urethra with transitional cell carcinoma of the bladder. BJU Int 1999;83:722-3. http://dx.doi.org/10.1046/i.1464-410x.1999.00071.x

6. Kageyama $S$, Suzuki K, Ushiyama T, et al. Primary localized amyloidosis of the urethra in a woman. $B r$ J Urol 1998;81:918-9. http://dx.doi.org/10.1046/i.1464-410x.1998.00702.x

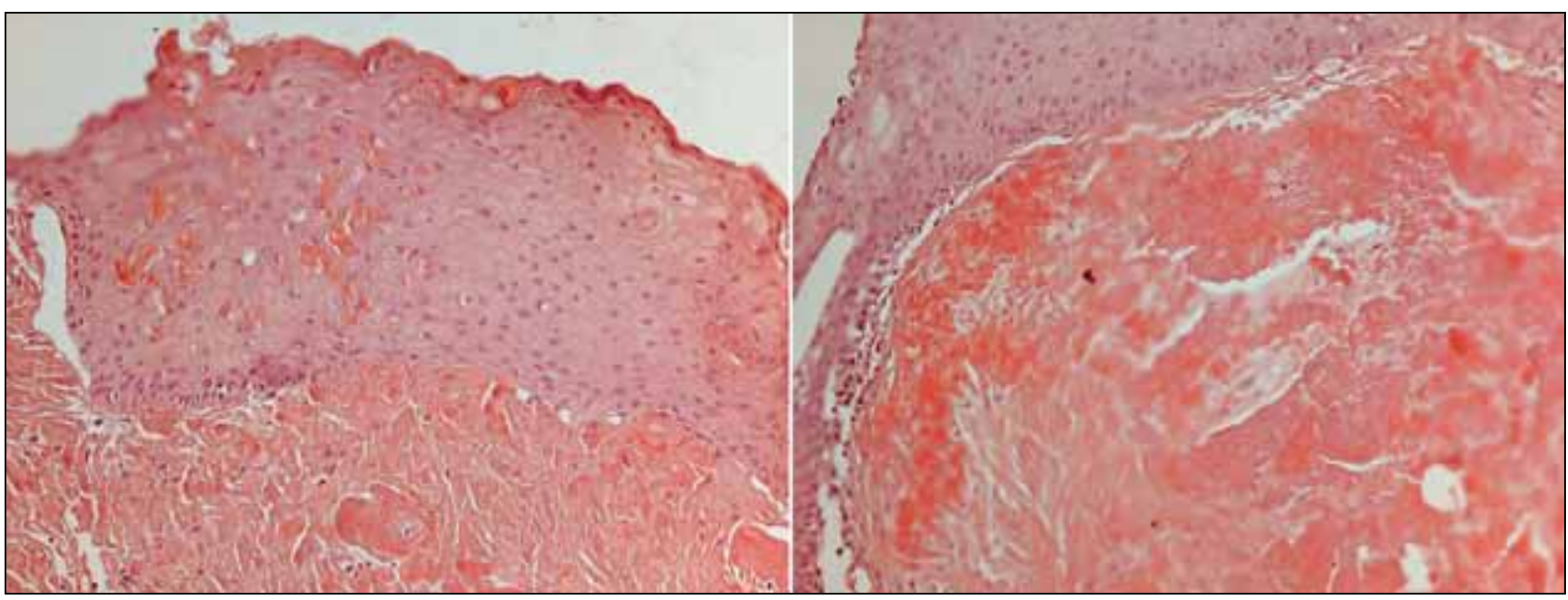

Fig. 4. Urethral biopsy specimens. A: Amyloid amorphous deposits in the mucosa of spongious urethra, stained with hematoxylin and eosin; B: Congo-red stain highlighting amyloid deposits (magnification $\times 200$ ). 
7. Miyamoto S, Tamiya T, Takatsuka K, et al. Primary localized amyloidosis of the urethra. Urology 1991;37:576-8. http://dx.doi.org/10.1016/0090-4295(91)80329-6

8. Provet JA, Mennen J, Sabatini M, et al. Primary amyloidosis of the urethra. Urology 1989;34:106-8. http://dx.doi.org/10.1016/0090-4295(89)90175-1

9. Sakuma S, Miyazaki T, Hirata H. A case of primary localized amyloidosis of the penile urethra. Int I Urol 1996;3:163-4. http://dx.doi.org/10.1111/i.1442-2042.1996.tb00506.x

10. Mani S, Flynn SD, Duffy TP, et al. Isolated amyloidosis of the penile urethra and corpus spongiosum: A case report. J Urol 1993; 150:1915-6.

11. Cormio L, Sanguedolce F, Pentimone $S$, et al. Urethral corpus spongiosum amyloidosis presenting with urethrorhagia during erection. J Sex Med 2009;6:2915-7. http://dx.doi.org/10.1111/i.17436109.2009.01286.x
12. Takeda Y, Sekiyama S, Suzuki A, et al. Localized oral amyloidosis: Ultrastructural and immunohistochemical study. J Oral Pathol 1987;16:278-81. http://dx.doi.org/10.1111/j.1600-0714.1987.tb01493.x

Correspondence: Dr. Miroslav L. Djordjevic, School of Medicine; University of Belgrade, Tirsova 10, Belgrade 11000, Serbia; djordjevi@@uromiros.com 